\title{
Autism and intellectual disability in a patient with two microdeletions in 6q16: a contiguous gene deletion syndrome?
}

\author{
Daniela Strunk $^{1^{*}} \mathbb{D}$, Peter Weber ${ }^{2}$, Benno Röthlisberger ${ }^{3}$ and Isabel Filges ${ }^{4}$
}

\begin{abstract}
Background: Copy number variations play a significant role in the aetiology of developmental disabilities including non-syndromic intellectual disability and autism.

Case presentation: We describe a 19-year old patient with intellectual disability and autism for whom chromosomal microarray (CMA) analysis showed the unusual finding of two de novo microdeletions in cis position on chromosome 6q16.1q16.2 and 6q16.3. The two deletions span 10 genes, including FBXL4, POU3F2, PRDM13, CCNC, COQ3 and GRIK2. We compared phenotypes of patients with similar deletions and looked at the involvement of the genes in neuronal networks in order to determine the pathogenicity of our patient's deletions.

Conclusions: We suggest that both deletions on $6 \mathrm{q}$ are causing his disease phenotype since they harbour several genes which are implicated in pathways of neuronal development and function. Further studies regarding the interaction between PRDM13 and GRIK2 specifically may be interesting.
\end{abstract}

Keywords: Autism, Intellectual disability, 6 q16 deletion, GRIK2, PRDM13

\section{Background}

Copy number variations $(\mathrm{CNV})$ play a significant role in the aetiology of developmental disabilities including non-syndromic intellectual impairment and/or autism [1-3], accounting for about $10-20 \%$ of non-syndromic patients $[1,4,5]$. In addition, mutations in numerous genes have been linked to the aetiology of intellectual disability (ID) [1] and autism spectrum disorders (ASD). Reduced penetrance and variable expressivity of CNVs and mutations add to the complexity of interpretation of causality. Therefore, although known to be highly heritable, the aetiology of ASD is still poorly understood with no single candidate gene accounting for a majority of ASD susceptibility [6-8]. Interpretation of the clinical significance of CNVs and evaluation of their contribution to the phenotype remains challenging, although CMAs are now widely used for diagnostic purposes.

We report on a patient with global developmental delay/intellectual disability (DD/ID) and autism for

\footnotetext{
* Correspondence: daniela.strunk@stud.unibas.ch

${ }^{1}$ Medical Genetics, University Hospital Basel, Schönbeinstrasse 40, CH-4031

Basel, Switzerland

Full list of author information is available at the end of the article
}

whom CMA analysis revealed the unusual finding of two microdeletions on chromosome 6q. Familial segregation analysis confirmed de novo events and cis-configuration of both deletions. Phenotype-genotype correlations of all genes within the deletions allowed to determine a likely pathogenic contribution of both deletions. Genes within both deletions are involved in ASD pathways and likely represent a contiguous gene deletion syndrome.

\section{Case presentation}

Our patient, which was last seen at 19 years of age, was the second of three children of healthy non- consanguineous Caucasian parents. The family history was unremarkable.

He was born at term after an uneventful pregnancy. Birth measurements were all above the 90th centiles with weight of $4750 \mathrm{~g}$ (>P 90), length of $55 \mathrm{~cm}(>\mathrm{P} 90)$ and occipitofrontal circumference (OFC) of $37 \mathrm{~cm}(>\mathrm{P}$ 90). Neonatal and infancy periods were unremarkable. The boy said his first words at 12 months and walked unsupportedly at 15 months of age. At age two, macrocephaly (above the 97th centiles for OFC) and stagnation 
of expressive speech as well as stereotypic behaviour and missing eye contact were noted.

At $6 \frac{1}{2}$ years the boy was diagnosed with infantile autism and severe intellectual disability. The results of the autism diagnostic observation schedule (ADOS) were above the cut-off for autism. In the Vineland adaptive behaviour scale he showed a severe developmental delay (developmental quotient 30); his social behaviour and communication behaviour met the level of a $1 \frac{1 / 2}{2}$ year old, and everyday life skills levels were comparable with a $2 \frac{1}{2}$ year old child. The boy had a very short attention span, showed stereotypic behaviour, hardly no functional or symbolic playing, almost no eye contact and minimal adaptive social skills. Expressive and receptive language skills were limited to simple orders.

Further regular follow-up exams at different ages confirmed the clinical findings. Except for a mild hypotonia neurological exams were in normal range. The patient developed dog phobia. No aggressivity or autoaggressivity was noted. Access to specialized school education and therapies as well as a stimulating familial environment allowed a certain independence in these surroundings. The patient today is able to ride a bicycle and swim. He still needs help with body hygiene.

At the last clinical exam at age 19 dysmorphic signs were a mild dolichocephalus, a low set hairline on the neck, a broad face, hypertelorism (IPD > 97 P), medial sparse eyebrows, bilateral prominent anthelices, posteriorly rotated ears, a short wide nose, full lips, widely spaced teeth, prominent upper incisors, long hands (hand length $>97 \mathrm{P}$ ), hyperextensible joints and a slight funnel chest. Measurements taken for OFC, weight and length were above the $97^{\text {th }}$ centile. The parents and siblings physical parameters are the following: mother $167 \mathrm{~cm}, 64 \mathrm{~kg}\left(\right.$ BMI $\left.22.9 \mathrm{~kg} / \mathrm{m}^{2}\right)$, father $187 \mathrm{~cm}, 98 \mathrm{~kg}$ (BMI $28 \mathrm{~kg} / \mathrm{m}^{2)}$, sister 1 and $2174 \mathrm{~cm}, 58 \mathrm{~kg}$ (BMI $19.2 \mathrm{~kg} / \mathrm{m}^{2}$ ) and $179 \mathrm{~cm}, 65 \mathrm{~kg}$ (BMI $20.3 \mathrm{~kg} / \mathrm{m}^{2}$ ), respectively.

Apart from frequent middle ear infections the patient was in good health. Extensive investigations in childhood which included brain magnetic resonance imaging (MRI), cranial computed tomography (CT), electroencephalogram and an abdominal ultrasound all proved unobtrusive. An X-ray of the hand performed at age 10 showed a slightly retarded bone age. Conventional chromosome analysis of lymphocytes (GTG-banding, 450 band level) did not show any numerical or structural anomalies. Specific testing for Fragile - X syndrome, Prader-Willi-, Angelman- and Beckwith-Wiedemann syndromes and for a 22q13 deletion did not show any abnormal results.

\section{Methods and results}

\section{Chromosomal microarray}

Array genomic hybridization of DNA from peripheral blood lymphocytes was performed in the patient and both his parents, using the NimbleGen WG HG18 Tiling $385 \mathrm{~K}$ CGHv.2.0 array. The tiling array version 2.0 contains 385,000 probes with a probe spacing of $6000 \mathrm{bp}$. Labelling and hybridization of test and reference DNA was performed according to manufacturer's protocols.

The analysis identified two deletions in $6 \mathrm{q}$ separated by a segment of $2 \mathrm{Mb}$. The proximal deletion (Deletion Nr.1) (Fig. 1) is an interstitial deletion localized in the chromosomal region 6q16.1q16.2, spanning $\sim 1.4 \mathrm{Mb}$ (chr6: 98,693,279-100,083,279 bp, hg19 build) and encompassing nine protein coding genes of which five are listed in the Online Mendelian Inheritance in Man (OMIM) database (Table 2).

The distal deletion (Deletion Nr.2), (Fig. 2) also an interstitial deletion, spans $760 \mathrm{~kb}$ and was assigned to the 6q16.3 chromosomal region (chr6: 102,113,307-102,873,307 bp, hg19 build). Its proximal breakpoint disrupts the GRIK2 gene in exon 3; coding exons 4-16 are therefore deleted. Results are shown in Fig. 3.

\section{Fluorescence in situ hybridization}

To further investigate the structural anomaly fluorescence-in-situ-hybridization (FISH) using the BlueGnome probes RP11-758C21 for 6q16.2 (green) and RP11-487 F5 for 6q16.3 (red) was done in the patient and his parents. The deletions were confirmed to be in cis-position in the patient. FISH analysis of the parents showed both loci to be present in correct position and orientation which proved a de novo origin of the deletions in the patient. There was no evidence for a complex structural rearrangement in the parents. FISH results are shown in Fig. 4.

\section{Sanger sequencing of GRIK2}

Because bi-allelic mutations in GRIK2 have been shown to cause autosomal recessive intellectual disability [9], we sequenced all 16 exons of the GRIK2 gene including exon-intron boundaries to confirm or rule out a compound heterozygous mutation on the second allele in GRIK2. No mutation was identified. Primer sequences can be obtained upon request.

\section{Genotype-phenotype correlations}

We searched current databases, specifically Decipher [10], ClinGen [11] and DGV [12] for overlapping copy number variations in patients or healthy individuals. Results of the overlapping pathogenic deletions 


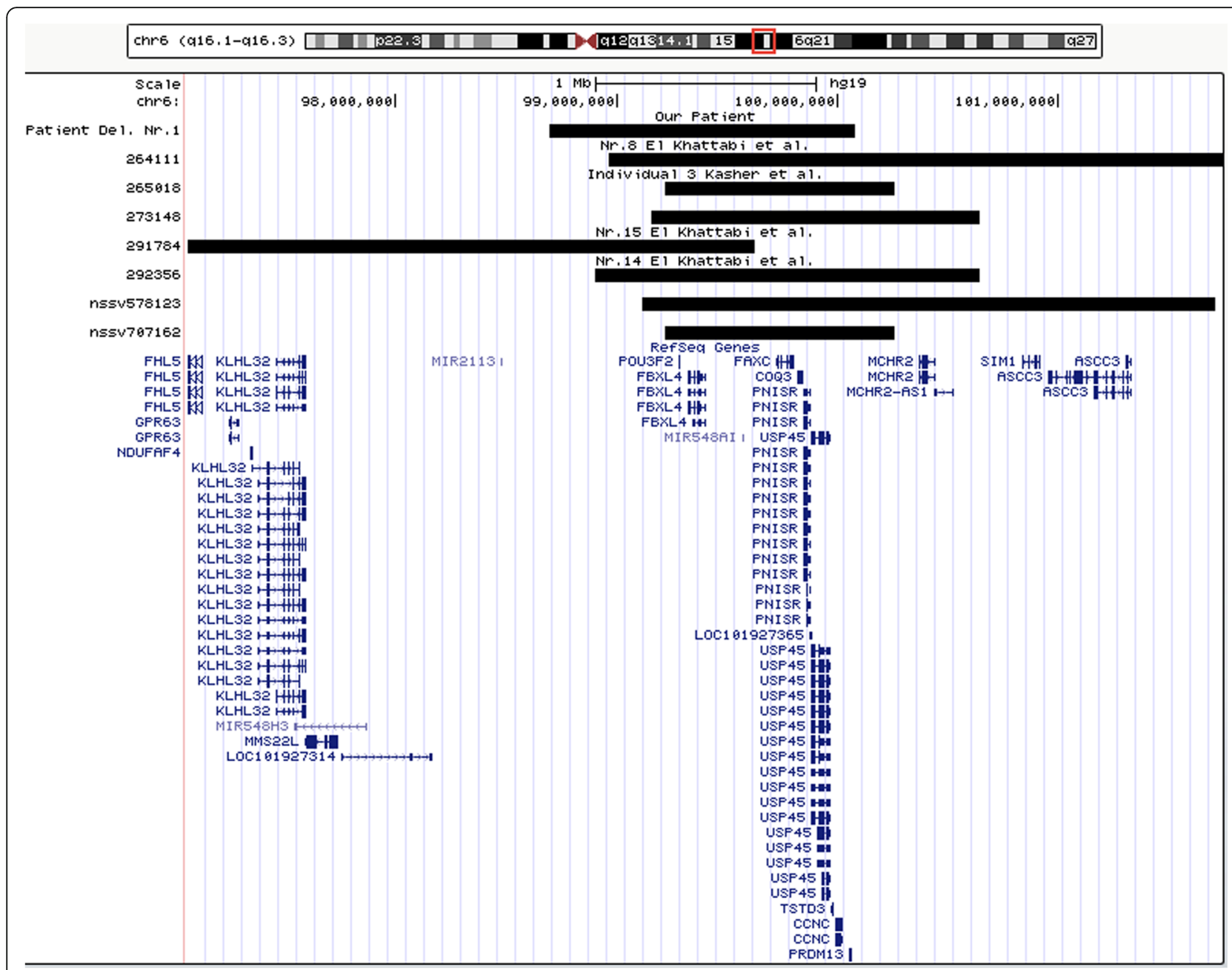

Fig. 1 UCSC genome browser, chromosomal region 6q16.1q16.3. The black bar marked "Patient del. Nr. 1" shows the proximal deletion of our patient, the other black bars patients with overlapping deletions as described in Table 1. RefSeq genes are depicted in blue

are shown in Table 1 . We performed an extended literature and database search on all genes included in the deleted regions, their functions and related phenotypes using PubMed [13] and OMIM [14]. Results are summarized in Table 2.

\section{Discussion}

Chromosomal microarray is now widely used as a diagnostic tool to elucidate the aetiology of developmental delay, intellectual disability and autism spectrum disorders. The genetic heterogeneity, reduced penetrance and

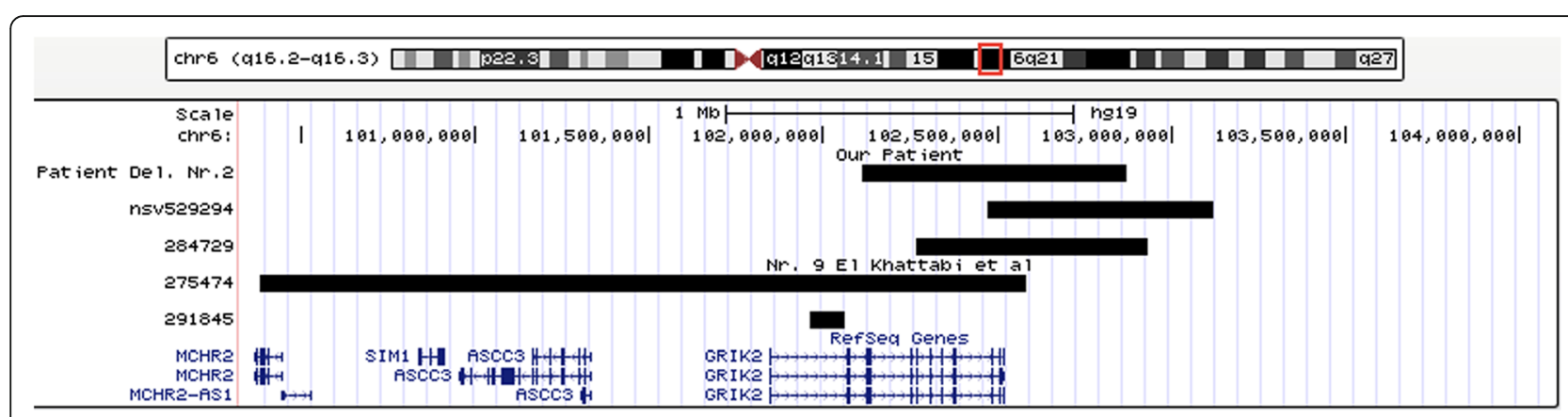

Fig. 2 UCSC genome browser, chromosomal region 6q16.2q16.3. The black bar marked "Patient del. Nr.2" shows the distal deletion of our patient, other black bars patients with overlapping or flanking deletions as described in Table 1. RefSeq genes are depicted in blue 


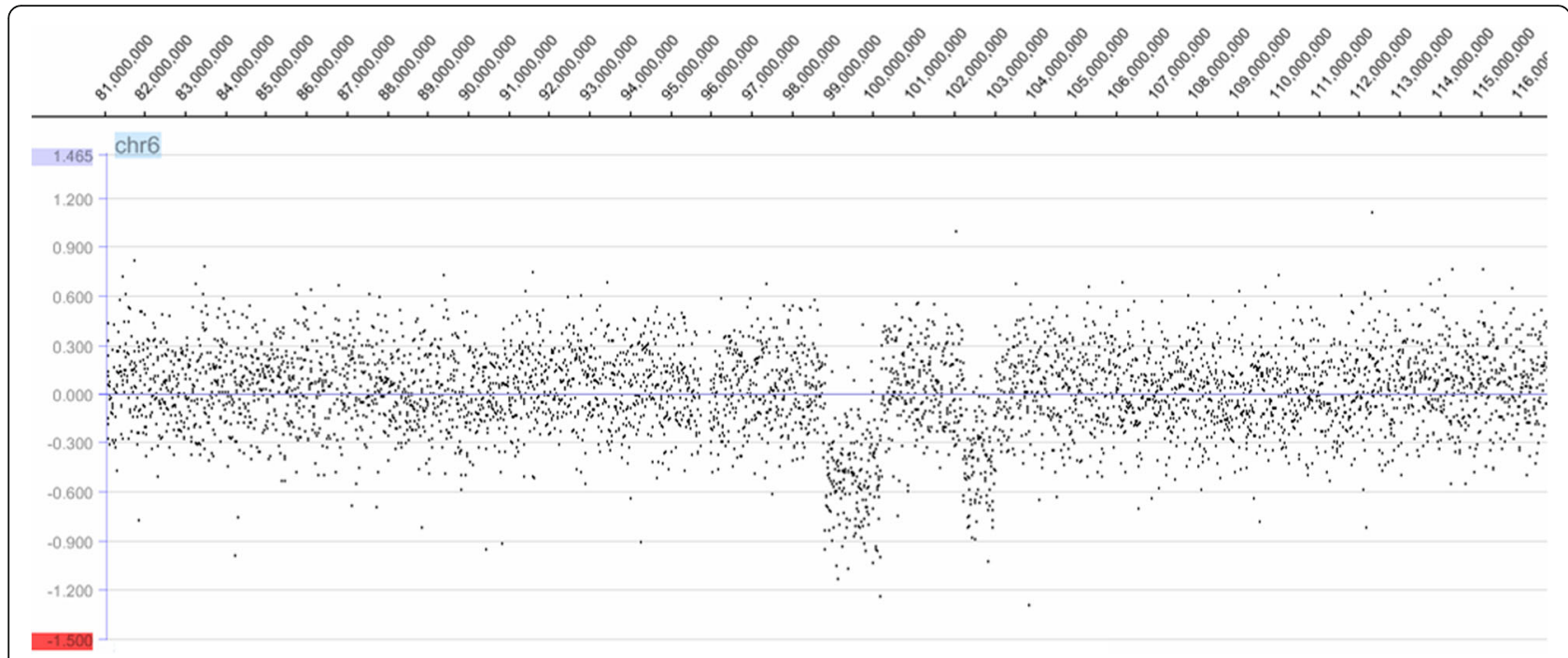

Fig. 3 Array plot of chromosome 6q. Deletion Nr. 1 is on 6q16.1q16.2 (chr6:98693279-100083279 bp); Deletion Nr. 2 on 6q16.3 (chr6:102113307102873307 bp). Hg version 19 (GRCh37/hg19)

variable expressivity as well as suggested polygenic versus monogenic inheritance often renders the interpretation of the causal contribution of single rare CNVs to these phenotypes difficult. Here, we report on a now adult patient with global developmental delay/intellectual disability and autism for which CMA analysis has revealed the unusual finding of two interstitial de novo microdeletions in cis-position on chromosome 6q. Both deletions, spanning $\sim 1.39 \mathrm{Mb}$ and $\sim 0.7 \mathrm{Mb}$ respectively, separated by a genomic segment of $\sim 2 \mathrm{Mb}$, have not been described before, but phenotype-genotype correlations with overlapping deletions mentioned in the medical literature and databases as well as haploinsufficiency of genes part of neuronal networks encompassed in both deletions, likely suggest their pathogenic contribution. Notably, Kasher et al. reported on several small heterozygous deletions in 6q16.1 presenting with variable developmental delay, intellectual disability and susceptibility to obesity. In one of their patients the deletion of 1.04 $\mathrm{Mb}$ includes the same nine genes as does the deletion Nr. 1 in the patient we describe [15]. The authors suggest a common critical region in their patients encompassing POU $3 F 2$.
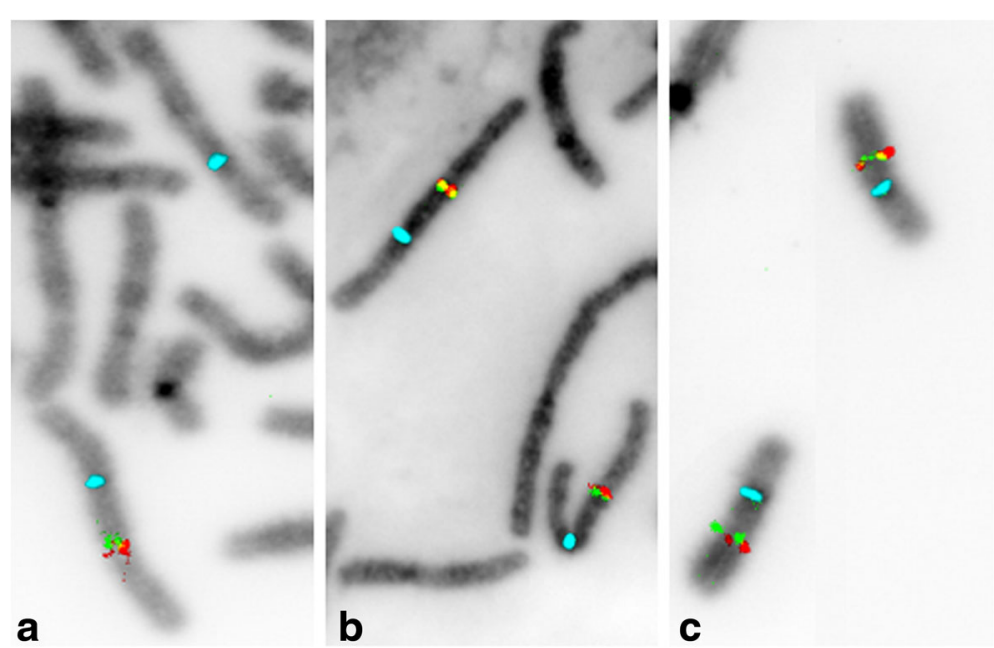

Fig. 4 Fluorescence- in-situ-hybridization (FISH) on metaphase spreads of the patient and his parents' chromosomes 6. We used the locus-specific Bluegnome probes RP11-758C21 for 6q16.2 (green), targeting deletion Nr 1, and RP11-487 F5 for 6q16.3 (red), targeting deletion nr.2, and the Abbott centromere specific probe cep 6 (aqua) for control. a Patient, b Patient's father, c Patient's mother: Both loci are present in correct orientation in the parent's FISH analysis and proved a de novo origin of the deletions in the patient. Deletions in the patient are in cis position 
Table 1 Overlapping deletions

\begin{tabular}{|c|c|c|c|}
\hline Decipher ID & Variant & Interval (Mb) & Phenotypes \\
\hline \multicolumn{4}{|l|}{ Overlapping deletion Nr. 1} \\
\hline Our patient & $\begin{array}{l}\text { loss: } \\
\text { 6:98693279-100083279 }\end{array}$ & 1.39 & $\begin{array}{l}\text { posterior rotated ears, macrocephaly, autism, } \\
\text { intellectual disability, speech impairment, hypertelorism, }\end{array}$ \\
\hline 264111 & $\begin{array}{l}\text { loss: } \\
\text { 6:98966910-101858361 }\end{array}$ & 2.89 & $\begin{array}{l}\text { behavioural/psychiatric abnormality, mild intellectual } \\
\text { disability, obesity [18] }\end{array}$ \\
\hline 291784 & $\begin{array}{l}\text { loss: } \\
\text { 6:96200844-99629252 }\end{array}$ & 3.43 & $\begin{array}{l}\text { abnormality of body height, abnormality of the ear, } \\
\text { abnormality of the nasal bridge, behavioural/psychiatric } \\
\text { abnormality, cognitive impairment, high forehead, } \\
\text { macrocephaly, neurological speech impairment, } \\
\text { overgrowth [18] }\end{array}$ \\
\hline $\begin{array}{l}\text { Variant Call ID } \\
\text { nssv707162 } \\
\text { (nsv533449) }\end{array}$ & $\begin{array}{l}\text { loss: } \\
\text { 6:99218523-100260987 }\end{array}$ & 1.04 & $\begin{array}{l}\text { abnormality of the heart } \\
\text { global developmental delay }\end{array}$ \\
\hline $\begin{array}{l}\text { dbVar ID } \\
\text { nsv530906 } \\
\text { (Variant Call ID: nssv578123) }\end{array}$ & $\begin{array}{l}\text { loss: } \\
\text { 6:99116405-101714826 }\end{array}$ & 2.59 & global developmental delay \\
\hline 292356 & $\begin{array}{l}\text { loss: } \\
\text { 6:98905933-100642867 }\end{array}$ & 1.37 & $\begin{array}{l}\text { development delay, learning disabilities, behavioural } \\
\text { disorders, brachycephaly, triangular face shape, unilateral } \\
\text { cryptorchism, strabismus [18] }\end{array}$ \\
\hline 265018 & $\begin{array}{l}\text { loss: } \\
\text { 6:99218535-100260996 }\end{array}$ & 1 & $\begin{array}{l}\text { neonatal hypotonia, mild motor delay, moderate learning } \\
\text { disability, speech delay, very severe obesity (BMI 47), } \\
\text { hyperphagia, behavioural problems [14] }\end{array}$ \\
\hline 273148 & $\begin{array}{l}\text { loss: } \\
\text { 6:99156238-100644046 }\end{array}$ & 1.49 & $\begin{array}{l}\text { severe intellectual disability, lipoma of the CNS, round } \\
\text { face, congenital muscular torticollis, plagiocephaly, } \\
\text { thoracolumbar scoliosis }\end{array}$ \\
\hline \multicolumn{4}{|l|}{ Overlapping deletion Nr.2 } \\
\hline Our patient & $\begin{array}{l}\text { loss: } \\
\text { 6:102113307-102873307 }\end{array}$ & 0.7 & $\begin{array}{l}\text { posterior rotated ears, macrocephaly, autism, intellectual } \\
\text { disability, speech impairment, hypertolerism, }\end{array}$ \\
\hline $\begin{array}{l}\text { dbVar ID } \\
\text { nsv529294 }\end{array}$ & $\begin{array}{l}\text { loss: } \\
\text { 6:102474505-103122745 }\end{array}$ & 0.6 & global developmental delay \\
\hline 275474 & $\begin{array}{l}\text { loss: } \\
\text { 6:100382250-102582366 }\end{array}$ & 2.2 & $\begin{array}{l}\text { perinatal hypotonia, developmental delay, learning } \\
\text { disabilities, behavioural disorders, hyperphagia, obesity, } \\
\text { synophris, hirsutism, small mouth [18] }\end{array}$ \\
\hline 284729 & $\begin{array}{l}\text { loss: } \\
\text { 6:102266317-102931873 }\end{array}$ & 0.7 & autistic behaviour \\
\hline \multicolumn{4}{|l|}{ Flanking deletion Nr. 2} \\
\hline 291845 & $\begin{array}{l}\text { loss: } \\
\text { 6:101962579-102060754 }\end{array}$ & 0.1 & autism, moderate global developmental delay \\
\hline
\end{tabular}

Deletions spanning $\leq 3.5 \mathrm{Mb}$ with a specified phenotype overlapping or flanking with the deletion in our patient as mentioned in the Decipher (decipher.sanger.ac.uk/browser) and ClinGen (www.clinicalgenome.org/data-sharing/) databases as well as referenced in the medical literature

POU3F2/Brn2 belongs to a family of transcription factors that share a highly homologous POU domain and is highly expressed in the central nervous system [16], especially the human hypothalamus and hippocampus [15]. POU3F2 upregulates proneuronal genes [16], promotes neurogenesis in the neocortex and is required for cortical neural migration [17]. Kasher et al. showed that in zebrafish, POU3F2 functions as a downstream target of SIM1 in the leptin - melanocortin - SIM1 pathway and plays a role in the regulation of oxytocin expression in the hypothalamus. They suggest POU $3 F 2$ being the likely causal mechanism affecting hypothalamic functions such as the control of food intake and social behaviour or learning, compatible with the human phenotypes in 6q16.1 deletions [15].

Previously, Bonaglia et al. [18], Griswold et al. [5], El Khattabi el al. [19] and Le Caignec et al. [20] reported on patients with mostly larger heterozygous deletions in $6 \mathrm{q} 16$ (in a range between 1.7 and $14 \mathrm{Mb}$ ) which do not allow specific phenotype-genotype correlations. However, their patients, the patients summarized in Table 1 and our patient share phenotypic findings such as hypotonia, intellectual disability, developmental delay as well as autistic features or behavioural anomalies reminiscent of ASD. Macrocephaly and tall stature and/or obesity are shared physical findings in some patients compatible 
Table 2 Involved genes

\begin{tabular}{|c|c|c|c|c|c|}
\hline Chromosome & $\begin{array}{l}\text { Gene/OMIM } \\
\text { number }\end{array}$ & Patient phenotype & Gene function & Resource & Mendelian inheritance \\
\hline \multicolumn{6}{|l|}{ Deletion Nr. 1} \\
\hline 6 & FBXL4/605654 & $\begin{array}{l}\text { mtDNA depletion syndrome } \\
\text { (infantile encephalomyopathic } \\
\text { type) }\end{array}$ & $\begin{array}{l}\text { Coding for a member of the F-Box family } \\
\text { (targeting substrates for degradation of } \\
\text { cellular regulatory proteins) } \\
\text { Maintenance of mtDNA } \\
\% H I \text { score } 10.28\end{array}$ & {$[31-33]$} & recessive \\
\hline 6 & POU3F2/600494 & None described & $\begin{array}{l}\text { POU domain transcription factor } \\
\text { predominantly expressed in the CNS. } \\
\text { Likely playing an important role in } \\
\text { mammalian neurogenesis and neuronal } \\
\text { migration in the neocortex, positive } \\
\text { regulator of Schwann cell development, } \\
\text { downstream target of SIM1 } \\
\% \mathrm{HI} \text { score } 15.18\end{array}$ & {$[15-17,34]$} & Unknown \\
\hline 6 & PRDM13/616741 & $\begin{array}{l}\text { North Carolina Macular } \\
\text { Dystrophy (NCMD), no } \\
\text { other neurologic } \\
\text { phenotype described }\end{array}$ & $\begin{array}{l}\text { Prdm transcription factor, neural specific } \\
\text { direct target of Ptf1a, controlling balance } \\
\text { of inhibitory and excitatory neurons in } \\
\text { somatosensory circuits during neuronal } \\
\text { development, } \\
\text { Required to produce the right number } \\
\text { of pax } 2+\text { neurons in the dorsal spinal cord } \\
\text { by repressing excitatory cell fate } \\
\% \mathrm{Hl} \text { score } 56.20\end{array}$ & {$[25,35,36]$} & $\begin{array}{l}\text { dominant for NCMD, } \\
\text { otherwise unknown }\end{array}$ \\
\hline 6 & CCNC/123838 & None described & $\begin{array}{l}\text { Member of the cyclin family, } \\
\text { Protein kinase in the RNA polymerase ॥ } \\
\text { complex, cell cycle regulator } \\
\% \mathrm{HI} \text { score } 2.44\end{array}$ & {$[30,37]$} & $\begin{array}{l}\text { Unknown, Protein } \\
\text { involved in } \\
\text { pathogenesis of } \\
\text { tumour development } \\
\text { and Alzheimer disease }\end{array}$ \\
\hline 6 & COQ3/605196 & None described & $\begin{array}{l}\text { Encodes an O-Methyltransferase, involved } \\
\text { in two steps of Ubiquinone (Coenzyme } \\
\text { Q10) biosynthesis } \\
\% H I \text { score } 40.90\end{array}$ & {$[29,38]$} & Unknown \\
\hline \multicolumn{6}{|l|}{ Deletion Nr. 2} \\
\hline 6 & GRIK2/138244 & $\begin{array}{l}\text { Intellectual disability; } \\
\text { ASD; behavioural } \\
\text { disorder, epilepsy, } \\
\text { dystonia }\end{array}$ & $\begin{array}{l}\text { Encodes for the glutamate receptor } 6 \text {, } \\
\text { excitatory neurotransmission in the brain } \\
\% \mathrm{HI} \text { score } 2.34\end{array}$ & {$[5,6,9,18,22,39]$} & $\begin{array}{l}\text { recessive; } \\
\text { susceptibility gene }\end{array}$ \\
\hline
\end{tabular}

Deletion 1 of our patient encompasses 9 genes, including FBXL4, POU3F2, CCNC, USP45, PNISR, FAXC, TSTD3, COQ3 and PRDM13. Deletion 2 partially encompasses GRIK2 (details see text). In this table only genes are listed with a known function described in OMIM (www.omim.org) or PubMed (http://www.ncbi.nlm.nih.gov/ pubmed). Haploinsufficiency score (\%HI) is mentioned as given in the Decipher database. HI score: predicted probability of exhibiting haploinsufficiency. High ranks 0-10\% more likely to exhibit haploinsufficiency, low ranks $90-100 \%[40]$

with a contribution of the genomic region to growth regulation. El Khattabi et al. suggested an involvement of the MCHR2 and SIM1 genes in behavioural disorders and SIM1 in obesity [19]. Both genes are not located within the deleted region of our patient. The normal BMI and feeding habits in our patient are in keeping with the finding of an incomplete obesity phenotype in the cohort of El Khattabi et al.

Of further interest, each of the two deletions in our patient span genes which have been described to play a significant role in the pathogenesis of autism $[5,6,18$, 21] and intellectual disability [22] due to their common roles in ASD associated pathways (Table 2). Particularly, the genes GRIK2, disrupted and partially deleted by deletion 2 in our patient, and PRDM13, encompassed by deletion 1 , are functionally linked.
Barbon and co-workers showed experimental evidence that several different splicing variants exist, and splicing mechanisms lead to truncated subunit isoforms suggesting a complex GluR system [23]. Zhawar et al. found GluR6 receptor subunits to be differentially expressed with expression of the GluR6A variant specifically in brain [24]. Studies on mice lacking the GluK2 subunit of kainate receptors, for which GRIK2 encodes, observed reduced social interaction and altered executive functions. The homozygous knockout of the GRIK2 gene produces a lower capacity for pattern separation and an increased propensity for pattern completion [8]. Patients with homozygous mutations in GRIK2 present with autosomal recessive intellectual disability [22]. In addition, studies on CNVs in ASD phenotypes suggest a contributory role of GRIK2 haploinsufficiency in ASD 


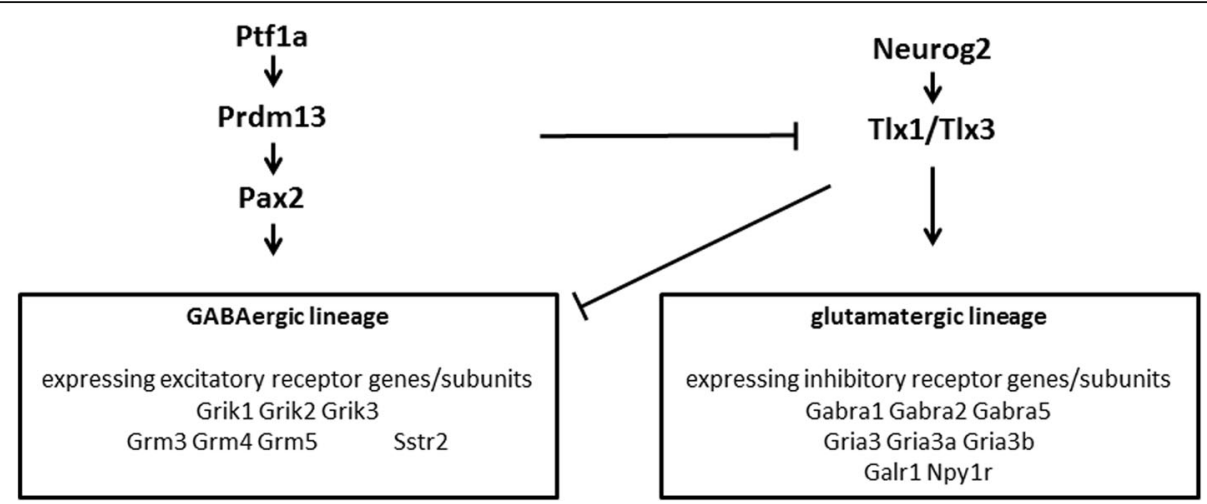

Fig. 5 In the dorsal spinal cord PRDM13 is required to produce the correct number of pax2+/GABAergic neurons [25]. Excitatory and inhibitory neurons of the dorsal spinal cord emerge from progenitor populations within the dorsal neural tube. Depending on the transcription factors that are expressed progenitors can become neurons in either class. To redirect cell fate such a transcription factor activates lineage specific gene expression of one lineage and represses the expression of genes in the alternate lineage. The inhibitory (GABAergic) lineage of neurons for example is specified by the homeodomain (HD) transcription factor Pax2. Pax2 and PRDM13 are required for the specification of inhibitory cell fate in the dorsal spinal cord and are direct downstream targets of Ptf1a. The excitatory (glutamatergic) lineage is specified by the HD factors TIx1/3. PRDM13 actively represses excitatory cell fate by binding to regulatory sequences near TIX1/T|x3 genes, suppressing their expression. Ptf1a, a transcription activator induces factor Pax2 while suppressing the expression of T|x1/3 which leads - through PRDM13- to an increase of inhibitory neurons at the expense of excitatory neurons. Adapted from Guo et al. [26] and Chang et al. [25]

$[5,18,20,21]$. The small size of the deletion reported by Griswold et al. supports the hypothesis of GRIK2 being a candidate gene for ASD.

GRIK2 is linked to the expression of PRDM13, a gene involved in neuronal development. PRDM13, a transcription factor, is a critical component in neuronal diversity and balance of inhibitory and exhibitory neurons in the dorsal spinal cord [25]. Most interestingly, cells of the inhibitory neuronal lineage in the dorsal spinal cord express excitatory receptor genes/subunits, among them GRIK2, indicating an interaction between excitatory and inhibitory neurons [26] (Fig. 5).

Based on these findings haploinsufficiency of all three genes POU3F2, GRIK2 and PRDM13 indicate a contribution of both deletions to our patient's phenotype and suggest their functional interaction as part of a contiguous gene deletion syndrome. However, the specific contribution of PRDM13 to human disease phenotypes remains to be further elucidated.

Griswold et al. identified several novel candidate genes in molecular pathways or genetic networks implicated in autism aetiology in a large genome-wide SNP array in a European ancestry case-control data set [5]. ASD candidate genes and their functional interactions are tightly linked with general dysregulation of gene expression, disturbances of neuronal maturation and pattering and may be key in conferring susceptibility to autism spectrum conditions [27]. Multi-dimensional co-expression analysis of ASD candidate genes in the normal developing human brain suggests the heterogeneous set of ASD candidates to share transcriptional networks related to synapse formation and elimination, protein turnover, and mitochondrial function [28]. The majority of genes encompassed in deletion Nr.1 (Table 2), in particular FBXL4, CCNC, POU $3 F 2$, PRDM13 and COQ3, can be considered part of these networks [16, 17, 25, 26, 29-31].

\section{Conclusions}

Recent research into gene interaction and networks in autism spectrum disorders and intellectual disability suggest that phenotype-related gene products are integral to neuronal development. It often remains difficult to draw firm conclusions as to the pathogenic contribution of each single $\mathrm{CNV}$ or mutation of these genes. However, we suggest that the two neighbouring deletions on $6 \mathrm{q}$ in our patient are likely to cause his ID/ASD phenotype since they harbour several genes implicated in different linked pathways of neuronal development and function.

\section{Abbreviations}

aCGH: Array comparative genomic hybridization; ADOS: Autism diagnostic observation schedule; ASD: Autism spectrum disorders; BMl: Body mass index; Bp: Base pairs; CMA: Chromosomal microarray analysis; CNV: Copy number variation; CoQ10: Coenzyme Q10; CT: Computer tomography; DD: Developmental delay; DGV: Database of genomic variants; DNA: Desoxyribonucleic acid; FISH: Fluorescence in-situ hybridization; GABA: Gamma-aminobutyric acid; GluK2/GRIK2: Glutamate receptor ionotropic, kainate 2; ID: Intellectual disability; IPD: Interpupillary distance; kb: Kilobases; Mb: Megabases; MRI: Magnetic resonance imaging; OFC: Occipitofrontal circumference; OMIM: Online mendelian inheritance in man; P: Percentile; SNP: Single nucleotide polymorphism

\section{Acknowledgments}

We would like to thank the patient and his family for their collaboration and consent.

Funding

Not applicable. 


\section{Availability of data and materials}

Not applicable.

\section{Authors' contributions}

DS wrote the manuscript, collected the data and performed the literature and data review; IF is responsible for and supervised the clinical assessment, genomic analysis and manuscript writing; PW contributed neurological data; BR performed the microarray analysis. All authors read and approved the final manuscript

\section{Competing interests}

The authors declare that they have no competing interests.

\section{Consent for publication}

Written informed consent was obtained from the patient's parents for publication of this case report and any accompanying images. A copy of the written consent is available for review by the Editor-in-Chief of this journal.

\section{Ethics approval and consent to participate}

Not applicable.

\section{Author details}

${ }^{1}$ Medical Genetics, University Hospital Basel, Schönbeinstrasse 40, CH-4031 Basel, Switzerland. 'Division of Neuropediatrics and Developmental Pediatrics, University Children's Hospital, Spitalstrasse 33, CH-4056 Basel, Switzerland. ${ }^{3}$ Medical Genetics, Department of Laboratory Medicine, Cantonal Hospital Aarau, Tellstrasse, CH-5001 Aarau, Switzerland. ${ }^{4}$ Medical Genetics, University Hospital Basel and University of Basel, Schönbeinstrasse 40, $\mathrm{CH}-4031$ Basel, Switzerland.

Received: 21 July 2016 Accepted: 21 November 2016

Published online: 03 December 2016

\section{References}

1. Filges I, et al. Deletion in Xp22.11: PTCHD1 is a candidate gene for X-linked intellectual disability with or without autism. Clin Genet. 2011;79(1):79-85.

2. Stankiewicz P, Beaudet AL. Use of array CGH in the evaluation of dysmorphology, malformations, developmental delay, and idiopathic mental retardation. Curr Opin Genet Dev. 2007;17(3):182-92.

3. Shaw-Smith C, et al. Microarray based comparative genomic hybridisation (array-CGH) detects submicroscopic chromosomal deletions and duplications in patients with learning disability/mental retardation and dysmorphic features. J Med Genet. 2004;41(4):241-8.

4. de Vries BBA, et al. Diagnostic genome profiling in mental retardation. Am J Hum Genet. 2005;77(4):606-16.

5. Griswold AJ, et al. Evaluation of copy number variations reveals novel candidate genes in autism spectrum disorder-associated pathways. Hum Mol Genet. 2012;21(15):3513-23.

6. Casey JP, et al. A novel approach of homozygous haplotype sharing identifies candidate genes in autism spectrum disorder. Hum Genet. 2012;131 (4):565-79.

7. Gvozdjáková A, Kucharská J, Ostatníková D, Babinská K, Nakládal D, Crane FL. Ubiquinol improves symptoms in children with autism. Oxid Med Cell Longev. 2014;2014:798957.

8. Micheau J, Vimeney A, Normand E, Mulle C, Riedel G. Impaired hippocampus-dependent spatial flexibility and sociability represent autismlike phenotypes in GluK2 mice. Hippocampus. 2014;24(9):1059-69.

9. Motazacker MM, et al. A defect in the ionotropic glutamate receptor 6 gene (GRIK2) is associated with autosomal recessive mental retardation. Am J Hum Genet. 2007:81(4):792-8.

10. DECIPHER v9.3: Mapping the clinical genome. [Online]. Available: https://decipher.sanger.ac.uk/. Accessed 17 Nov 2015.

11. ClinGen - ClinGen / Clinical Genome Resource. [Online]. Available: https://www.clinicalgenome.org/. Accessed 17 Nov 2015.

12. Database of Genomic Variants. [Online]. Available: http://dgv.tcag.ca/ dgv/app/home?ref = GRCh37/hg19. Accessed 26 Oct 2016

13. Home - PubMed - NCBI. [Online]. Available: http://www.ncbi.nlm.nih.gov/ pubmed. Accessed 17 Nov 2015.

14. OMIM - Online Mendelian Inheritance in Man. [Online]. Available: http://www. omim.org/. Accessed 09 Nov 2016.
15. Kasher PR, et al. Small 6q16.1 deletions encompassing POU3F2 cause susceptibility to obesity and variable developmental delay with intellectual disability. Am J Hum Genet. 2016;98(2):363-72.

16. Dominguez MH, Ayoub AE, Rakic P. POU-III transcription factors (Brn1, Brn2, and Oct6) influence neurogenesis, molecular identity, and migratory destination of upper-layer cells of the cerebral cortex. Cereb Cortex N Y N 1991. 2013;23(11):2632-43.

17. McEvilly RJ, de Diaz MO, Schonemann MD, Hooshmand F, Rosenfeld MG. Transcriptional regulation of cortical neuron migration by POU domain factors. Science. 2002;295(5559):1528-32.

18. Bonaglia $M C$, et al. Detailed phenotype-genotype study in five patients with chromosome $6 q 16$ deletion: narrowing the critical region for Prader-Willilike phenotype. Eur J Hum Genet. 2008;16(12):1443-9.

19. El Khattabi $L$, et al. Incomplete penetrance and phenotypic variability of 6q16 deletions including SIM1'. Eur J Hum Genet. 2015:23(8):1010-8.

20. Le Caignec C, Swillen A, Van Asche E, Fryns J-P, Vermeesch JR. Interstitial 6q deletion: clinical and array CGH characterisation of a new patient. Eur J Med Genet. 2005;48(3):339-45.

21. Jamain $\mathrm{S}$, et al. Linkage and association of the glutamate receptor 6 gene with autism. Mol Psychiatry. 2002;7(3):302-10.

22. Poot M, Eleveld MJ, van 't Slot R, Ploos van Amstel HK, Hochstenbach R. Recurrent copy number changes in mentally retarded children harbour genes involved in cellular localization and the glutamate receptor complex. Eur J Hum Genet. 2010;18(1):39-46.

23. Barbon A, Vallini I, Barlati S. Genomic organization of the human GRIK2 gene and evidence for multiple splicing variants. Gene. 2001:274(1-2):187-97.

24. Zhawar VK, Kaur G, deRiel JK, Kaur GP, Kandpal RP, Athwal RS. Novel spliced variants of ionotropic glutamate receptor GluR6 in normal human fibroblast and brain cells are transcribed by tissue specific promoters. Gene. 2010;459(1-2):1-10.

25. Chang JC, et al. Prdm13 mediates the balance of inhibitory and excitatory neurons in somatosensory circuits. Dev Cell. 2013:25(2):182-95.

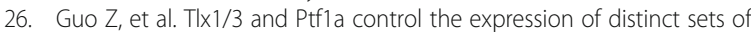
transmitter and peptide receptor genes in the developing dorsal spinal cord. J Neurosci. 2012;32(25):8509-20

27. Casanova EL, Sharp JL, Chakraborty H, Sumi NS, Casanova MF. Genes with high penetrance for syndromic and non-syndromic autism typically function within the nucleus and regulate gene expression. Mol Autism. 2016:7:18.

28. Mahfouz A, Ziats MN, Rennert OM, Lelieveldt BPF, Reinders MJT. Shared pathways among autism candidate genes determined by co-expression network analysis of the developing human brain transcriptome. J Mol Neurosci. 2015;57(4):580-94.

29. Jonassen T, Clarke CF. Isolation and functional expression of human COQ3, a gene encoding a methyltransferase required for ubiquinone biosynthesis. J Biol Chem. 2000:275(17):12381-7.

30. Li H, et al. Molecular cloning and chromosomal localization of the human cyclin C (CCNC) and cyclin E (CCNE) genes: deletion of the CCNC gene in human tumors. Genomics. 1996;32(2):253-9.

31. Cenciarelli C, Chiaur DS, Guardavaccaro D, Parks W, Vidal M, Pagano M. Identification of a family of human F-box proteins. Curr Biol. 1999;9(20):1177-9.

32. Bonnen PE, et al. Mutations in FBXL4 cause mitochondrial encephalopathy and a disorder of mitochondrial DNA maintenance. Am J Hum Genet. 2013;93(3):471-81.

33. Winston JT, Koepp DM, Zhu C, Elledge SJ, Harper JW. A family of mammalian F-box proteins. Curr Biol. 1999:9(20):1180-2.

34. Jaegle $M$, et al. The POU proteins Brn-2 and Oct- 6 share important functions in Schwann cell development. Genes Dev. 2003:17(11):1380-91.

35. Hanotel J, et al. The Prdm13 histone methyltransferase encoding gene is a PtflaRbpj downstream target that suppresses glutamatergic and promotes GABAergic neuronal fate in the dorsal neural tube. Dev Biol. 2014;386(2):340-57.

36. Hohenauer T, Moore AW. The Prdm family: expanding roles in stem cells and development. Dev Camb Engl. 2012;139(13):2267-82.

37. Ueberham U, Hessel A, Arendt T. Cyclin C expression is involved in the pathogenesis of Alzheimer's disease. Neurobiol Aging. 2003;24(3):427-35.

38. Marbois BN, Xia YR, Lusis AJ, Clarke CF. Ubiquinone biosynthesis in eukaryotic cells: tissue distribution of mRNA encoding 3,4-dihydroxy-5polyprenylbenzoate methyltransferase in the rat and mapping of the $\mathrm{COQ} 3$ gene to mouse chromosome 4. Arch Biochem Biophys. 1994;313(1):83-8.

39. Córdoba M, Rodriguez S, González Morón D, Medina N, Kauffman MA Expanding the spectrum of Grik2 mutations: intellectual disability, behavioural disorder, epilepsy and dystonia. Clin Genet. 2015;87(3):293-5.

40. Huang N, Lee I, Marcotte EM, Hurles ME. Characterising and predicting haploinsufficiency in the human genome. PLoS Genet. 2010;6(10):e1001154. 